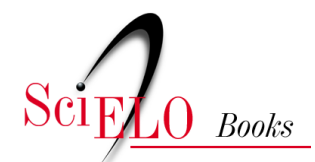

\title{
uerj
}

\section{Capítulo 6 - Legislativo e sociedade}

\author{
Vitor Oliveira
}

\section{SciELO Books / SciELO Livros / SciELO Libros}

OLIVEIRA, V. Legislativo e sociedade. In.: SANTOS, F., ed. Congresso remoto: a experiência legislativa brasileira em tempos de pandemia [online]. Rio de Janeiro, 2021, pp. 97-114. Sociedade e política collection. ISBN: 978-65-88808-12-2. https://doi.org/10.7476/9786588808122.0008.

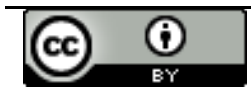

All the contents of this work, except where otherwise noted, is licensed under a Creative Commons Attribution 4.0 International license.

Todo o conteúdo deste trabalho, exceto quando houver ressalva, é publicado sob a licença Creative Commons Atribição 4.0.

Todo el contenido de esta obra, excepto donde se indique lo contrario, está bajo licencia de la licencia Creative Commons Reconocimento 4.0. 


\section{Capítulo 6 \\ LEGISLATIVO E SOCIEDADE}

Vitor Oliveira

\section{Introdução}

Desde a promulgação da Constituição Federal de 1988, a crescente participação política da sociedade civil organizada no processo legislativo tem sido uma das marcas do aprofundamento da democracia no Brasil, ainda que não de forma inexorável e monotônica.

Tal participação ganhou sofisticação ao longo da Nova República, passando a ter como características a regularidade e a profissionalização, bem como com organizações e redes exclusivamente dedicadas a utilizar dos meios legítimos para influenciar a formulação de políticas públicas e a tomada de decisão no âmbito do Poder Legislativo.

Assim como em todas as áreas da vida pública, este movimento encontrou importantes barreiras com a pandemia de Covid-19, cujo efeito mais dramático na política institucional deu-se com o fechamento do espaço físico do Congresso Nacional - e não apenas para o público, como também para os próprios parlamentares, assessores e equipes técnicas a partir de meados de março de 2020.

Com isto, limitou-se amplamente o emprego de algumas das principais metodologias e ferramentas de advocacy, como se convencionou chamar a participação política sistematizada da socie- 
dade civil, em especial as estratégias de relacionamento, lobbying e monitoramento presenciais.

Não obstante as dificuldades de mobilização política dentro e fora do parlamento, o ano de 2020 foi marcado por grande ativismo, especialmente nos momentos cruciais de definição das políticas públicas em resposta à pandemia de Covid-19, bem como nas tentativas de aproveitamento do vazio físico do parlamento para o benefício de grupos de interesse cujas agendas distanciam-se dos princípios de sustentabilidade socioambiental.

O presente capítulo buscará avaliar a atuação da sociedade civil nesse período por meio da conceituação de suas ações no âmbito da política institucional, bem como descrição e análise de dois casos emblemáticos de ação coletiva da sociedade civil, visando influenciar políticas públicas em nível federal.

Em que pese ter havido também intensa participação política nos planos estadual e municipal, este capítulo avaliará a forma como tais organizações e suas lideranças políticas resolveram problemas de coordenação e mobilização no plano federal, em um cenário de escassez das ferramentas tradicionais de lobbying.

Nesse contexto, foram fundamentais o senso de oportunidade, com o aproveitamento das janelas abertas pelo processo legislativo, bem como do capital político construído ao longo de anos pelas organizações, potencializados por estratégias de comunicação e mobilização virtuais.

Com a perda simbólica e concreta do espaço do Parlamento, e da legitimidade política que a institucionalidade traz, a alternativa encontrada pelas organizações foi buscar tal legitimidade por meio de estratégias de advocacy. Assim, foi relevante também a sinalização de amplitude ideológica da coalizão formada, por meio da estratégia de diversidade na seleção de porta-vozes, bem como de mobilização massiva, em escala poucas vezes vista fora de períodos eleitorais ou de impeachment. 


\section{Conceito em disputa}

Adotamos neste capítulo, o conceito de advocacy com o sentido de estratégias para a participação política sistematizada, cujo objetivo direto se relaciona à promoção e à defesa de causas, em oposição à defesa direta de interesses privados, articulando diversas ferramentas e metodologias para atingir o objetivo de, necessariamente, agir na origem dos problemas, visando impacto em larga escala e perenidade.

Quando mobilizadas por Organizações da Sociedade Civil (OSCs), advocacy diferencia-se da ação social humanitária ou em substituição à execução de políticas públicas pelo Estado, cujo impacto tende a ser menos amplo e intermitente.

Reconhecemos, contudo, que a definição acima está longe de ser consensual, havendo uma disputa política sobre a legitimidade e o alcance do uso do conceito entre organizações da sociedade civil e outros atores privados, grupos de interesse e até mesmo agências estatais (Gozetto, 2018).

Tal disputa conceitual ganha relevância no Brasil menos em função de sua carga normativa, do que pela imagem negativa que a atividade de defesa de interesses privados recebeu no Brasil, chamada pela mídia genericamente de "Lobby", associada sempre a manchetes sobre corrupção de agentes públicos e atividades criminosas.

Não se pretende aqui resolver tal querela, mas apenas dar clareza sobre como mobilizamos o conceito de forma analítica e o porquê de o utilizarmos para falar especificamente sobre a atividade política de organizações da sociedade civil.

Dentro desta perspectiva, mobilizamos o conceito de lobbying para definir as atividades de relacionamento e de influência sobre a escolha de tomadores de decisão, bem como sobre o processo de tomada de decisão em si e formulação e execução de políticas públicas. 
Seguimos a ideia de que lobby constitui a defesa de interesses junto a membros do poder público que podem tomar decisões referentes às políticas públicas (Mancuso e Gozetto, 2013), de forma genérica e neutra com relação a valores.

Portanto, estratégias de advocacy costumam incorporar elementos e metodologias de lobby como uma de suas ferramentas, assim como de comunicação social, produção de conhecimento, entre outras, como pretendemos ressaltar no decorrer do presente artigo, especialmente quando mobilizadas em conjunto e de forma articulada.

\section{Problemas fundamentais do Congresso remoto}

Por óbvio, a política institucional não cessou durante a pandemia. Sem o funcionamento regular do Parlamento, contudo, perdeu-se não apenas um espaço de deliberação, mas também um ambiente de encontro entre atores institucionais e da sociedade civil para coordenação, troca de informações técnicas e mobilização política.

Alguns espaços institucionais, como o das Comissões, não encontraram substitutos no sistema de deliberação remoto, cujo objetivo primordial era manter a capacidade de tomada de deliberação do Legislativo, mas que para isto centralizou as atividades nos plenários, em detrimento dos colegiados.

No caso das Frentes Parlamentares, cuja atuação varia muito, é possível dizer que as atividades foram mantidas de forma remota, por meio da realização de eventos, como reuniões de coordenação e seminários virtualmente, prática que já ganhava espaço em articulações como a Frente Parlamentar Ambientalista, que passou a fazer reuniões virtuais abertas semanalmente, bem como reuniões para 
coordenação entre parlamentares e organizações que a compõem, ${ }^{1}$ desde o mês de abril de 2020.

\subsection{Coalizões}

Tendo em vista a escassez de recursos para a atuação de qualquer organização, bem como as peculiaridades de financiamento das organizações da sociedade civil, torna-se imperativo entender suas ações estratégicas por meio de uma análise de custo-benefício.

Como tende a acontecer com ação coletiva, algumas das questões fundamentais ligadas à atuação de coalizões dizem respeito à provisão de um bem coletivo (advocacy) em um contexto de ausência de coerção.

Conforme afirmou Mancur Olson (2011, p. 14), "mesmo que todos os indivíduos de um grupo grande sejam racionais e centrados nos próprios interesses, e que saiam ganhando se, como grupo, agirem para atingir seus objetivos comuns, ainda assim eles não agirão voluntariamente para promover esses interesses comuns".

A tensão entre racionalidade individual e benefício coletivo é uma constante, embora mitigada pela existência de valores comuns que geram incentivos distintos aos da maximização de benefícios individuais.

Em uma análise de custo-benefício da atuação em grupos pequenos, Olson (2011, p. 35) ressalta que

[...] se uma determinada quantidade de um benefício coletivo puder ser obtida a um custo suficientemente baixo, com relação às vantagens que trará, a ponto de um ator sozinho do grupo em questão sair ganhando, mesmo que tenha de arcar sozinho com

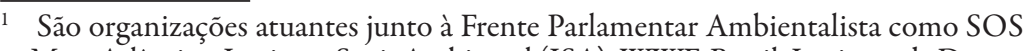
Mata Atlântica, Instituto SocioAmbiental (ISA), WWF-Brasil, Instituto de Desenvolvimento Sustentável (IDS), Ascema Nacional e Greenpeace. 
esse custo, então há uma boa probabilidade de que o benefício coletivo seja proporcionado.

A interrupção do espaço físico para atuação, significando menos ganhos no curto-prazo, e o aumento do custo para a obtenção de informações e realização de articulações podem explicar em parte o aumento dos benefícios relativos vistos pelas organizações no fortalecimento de coalizões durante a pandemia de Covid-19, deslocando os eixos em que se davam tradicionalmente as ações de coordenação e mobilização.

Sem o espaço físico, reforçou-se a necessidade de troca de informações por meio de redes sociais e políticas, o que conferiu especial destaque às coalizões perenes e ad hoc, como a Rede Advocacy Colaborativo (RAC) e as articulações em torno de frentes parlamentares, como a ambientalista.

Desde o primeiro semestre de 2017 , organizações da sociedade civil lideradas pela Fundação Avina passaram a discutir oportunidades para ações de incidência no processo político de forma conjunta, por meio da troca de informações e parcerias. Desde então a rede se fortaleceu, passou a se chamar RAC e contar com estruturas de secretariado e grupos temáticos, criando espaços regulares de troca e coordenação das organizações, o que criou uma estrutura favorável, utilizada em diversas ocasiões durante a pandemia.

Assim como em todas as esferas da vida, as atividades presenciais foram substituídas por reuniões virtuais desde a eclosão da pandemia. No caso da Rede Advocacy Colaborativo (RAC), estimativas de sua secretaria executiva apontam um incremento de $30 \%$ na quantidade de reuniões semanais e de $15 \%$ nas ações coordenadas, entre as mais de cem organizações que a integraram durante o período da pandemia. 


\subsection{A MP da "Grilagem”}

A Medida Provisória (MP) 910 teve origem antes mesmo do sistema de deliberação remoto, apresentada em 11 de dezembro de 2019, tendo sido designado por acordo de lideranças o senador Irajá Abreu (PSD/GO), figura próxima do setor agropecuário, como relator da Comissão Especial.

Desde o fim do recesso parlamentar em 2020, as organizaçôes, apoiadas pela Frente Parlamentar Ambientalista, já se orientavam pela estratégia que viria a ser potencializada com o advento da pandemia: mobilizar a opinião pública e carimbar na MP 910 a alcunha de "Grilagem", em vez do nome apresentado pelo Poder Executivo - "Regularização Fundiária" -, com o objetivo final de que a proposição fosse rejeitada, ou ao menos modificada de forma substantiva, como uma solução de compromisso.

De acordo com a avaliação das organizações, ao regularizar lotes grandes de terra (até 2.500 hectares), por meio da autodeclaração e por pessoas envolvidas em ocupações irregulares de terra anteriores, a medida estimularia a ocupação ilegal de terras sem focalizar nos pequenos produtores.

Tendo em vista o recesso parlamentar, houve poucos dias de trabalho presencial e o relator da comissão especial perdeu importância conforme a tramitação aproximou-se do fim do prazo de vigência da Medida Provisória.

Via de regra, os trabalhos da Comissão Mista Especial são o principal momento para incidência de organizações da sociedade civil na tramitação de medidas provisórias, quando propõem emendas por meio de parlamentares aliados, participam de audiências públicas e buscam o convencimento técnico e político da relatoria, antes da chegada dos textos aos plenários da Câmara e do Senado, cujo espaço de atuação é restrito.

Foi nesse cenário que as organizações da área ambiental se prepararam inicialmente para incidir no processo legislativo por meio de 
lobby junto ao relator, além da estratégia de comunicação mencionada anteriormente, relacionando a proposição à grilagem de terras.

Paulatinamente, com o avançar da crise, as organizações intensificaram suas ações de comunicação. No âmbito da RAC, o WWF-Brasil e o IDS coordenaram ações envolvendo dezenas de organizações chamadas de cyber advocacy, implicando o uso intensivo das redes sociais para mobilização contra a Medida Provisória 910, coordenada por meio de hashtags como “\#mp910Não!”, "\#GrilagemÉCrime" e “\#GrilagemNão", bem como de páginas na internet como "Saldão da Amazônia" (https://www.saldaodaamazonia.org. $\mathrm{br} /$ ), em que as pessoas poderiam acessar e enviar mensagens diretamente para os interlocutores-chave no processo legislativo.

Ao longo do processo, essas estratégias foram suficientes para que - sem o funcionamento da comissão mista -, o relator da MP 910 no plenário da Câmara dos Deputados, deputado Zé Silva (Solidariedade/MG), modificasse substancialmente pontos apontados pelas organizações como problemáticos.

Às vésperas do prazo para o encerramento da validade da medida provisória, e portanto da possibilidade de sua aprovação, o presidente da Câmara dos Deputados buscou a realização de um acordo para a aprovação da matéria. Não obstante, a posição da Frente Parlamentar Ambientalista - incorporada pela oposição - e das organizações que promoviam as ações de advocacy foi contrária à concretização do acordo.

$\mathrm{O}$ acordo foi fundamental não porque faltassem votos aos apoiadores da matéria, impulsionados pelo Planalto e pela Frente Parlamentar da Agropecuária, mas sim por conta das relações políticas estabelecidas desde a eleição de Rodrigo Maia para a presidência e a instauração dos procedimentos de votação pelo Congresso Remoto.

Informalmente, os partidos acordaram que o sistema de deliberação remoto seria utilizado apenas para a votação de medidas relativas à pandemia de Covid-19, ou para matérias sobre as quais houvesse acordo. 
Este argumento foi apresentado diversas vezes pelos partidos de oposição, que embora minoria, tiveram sua posição respeitada pelo presidente Rodrigo Maia, que afirmou durante a sessão do dia 12/5/2020:

[...] Quanto a esta matéria, de fato o Relator avançou muito. Tenho certeza de que, se não fosse o enfrentamento ideológico entre a bancada do agronegócio e a bancada do meio ambiente, hoje estariamos todos votando - estou dando a minha opinião - a favor do texto do Deputado Zé Silva. [...] Temos um caminho, que é, construída a maioria, que existe - não tenho dúvida nenhuma disso - , atropelarmos a minoria nesta Casa quanto a este tema, e temos o risco de, amanhã, desorganizar as relações entre todos os partidos. [...] A sessão remota, se nós não tivermos disciplina, nos atrapalha. Agora mesmo, a Deputada Adriana, mais uma vez, reclamou para mim, pelo Whatsapp, de falta de previsibilidade; muitos Líderes reclamam também de falta de previsibilidade nas pautas que serão votadas. [...] Eu proponho, Líderes Deputado Arthur, Deputado Vitor Hugo, Deputado Aguinaldo Ribeiro, Deputada Perpétua Almeida, Deputada Fernanda Melchionna, todos os Líderes que estão no painel, que, já que a proposta foi feita pelo MDB, o Líder Deputado Zé Silva apresente o projeto, e na próxima quarta-feira a Maioria exerça o seu direito, com respeito, tentando construir uma votação, como disse o Líder Deputado Paulo Ganime, em que também se respeite o gesto que está sendo feito neste momento (ênfases minhas).

Sem dizer textualmente, o presidente da Câmara tomou para si a decisão de retirar da pauta a Medida Provisória, com base na proposta do MDB para que um novo Projeto de Lei com o texto do relator Zé Silva fosse apresentado e aprovado, em lugar da MP. Este projeto, PL 2.633/2020, continua tramitando sem perspectiva 
de votação e sendo objeto de ações de advocacy das mesmas organizações da sociedade civil.

Ressalte-se que, a despeito da grilagem de terras ser um tema pouco saliente para a maior parte da população, a campanha de advocacy atingiu grande repercussão. Quando proferiu sua decisão, Rodrigo Maia havia sido diretamente interpelado por celebridades e influenciadores digitais não apenas do Brasil, mas de repercussão global.

\subsection{A renda emergencial}

A aprovação da renda básica emergencial de $\mathrm{R} \$ 600,00$ era longe de certa, em meados de março de 2020. Diferentemente da retórica governista que ganhou corpo após sua aprovação, a proposta inicial do Planalto dizia a um único voucher de $\mathrm{R} \$ 200,00$, sem especificação exata sobre outros aspectos fundamentais, como duração, alcance ou operacionalização.

Coube à sociedade civil organizada o papel de impulsionar a discussão, ampliar a pressão sobre os tomadores de decisão e até mesmo apontar os caminhos técnicos para seu financiamento e operacionalização, como mostraremos na descrição abaixo.

\subsection{Tramitação}

A proposta que se transformou na Lei 13.982/2020, em 2 de abril de 2020, teve origem no Projeto de Lei (PL) 9.236/2017, de autoria do deputado Eduardo Barbosa (PSDB/MG), mas cujo conteúdo foi sobremaneira modificado durante o processo legislativo pelo relator principal na Câmara, o deputado Marcelo Aro (PP/MG).

$O$ projeto de lei original propunha critérios adicionais, além da renda, para a concessão do Benefício de Prestação Continuada (BPC), em especial aquelas relacionadas a pessoas com deficiência e idosos. Até a pandemia, a proposição tramitava sem grande destaque, 
tendo recebido pareceres favoráveis das comissões dos Direitos da Pessoa Idosa (Cidoso) e dos Direitos das Pessoas com Deficiência (CPD). Antes de passar a tramitar com urgência, em 25/3/2020 e ir diretamente ao plenário, o PL 9.236/2017 encontrava-se na Comissão de Seguridade Social e Família (CSSF), já com relatório favorável.

Em plenário, o relator designado, deputado Marcelo Aro (PP/MG), propôs o substitutivo aprovado e que deu redação final à proposta, pouco modificada posteriormente pela Casa revisora no processo, o Senado Federal.

As redes sociais também foram palco da disputa sobre a responsabilidade pela medida, algo fartamente retratado pela mídia, ${ }^{2}$ mas que ignorou em grande parte o trabalho das organizações da sociedade civil organizada. Enquanto o presidente da República, em sua conta no Twitter, afirmou que "Depois de o Congresso apoiar R\$ 500,00 para o auxílio emergencial (...) o @MinEconomia alcançou os R\$600,00” (@jairbolsonaro, 11/6/2020), o relator rebateu, dizendo: "Presidente, isso não é verdade. Vamos contar a história real? Fui relator do projeto. Seu governo foi contra o meu relatório desde o primeiro momento. Vocês não admitiam um valor acima de R\$200,00” (@marceloaro, 11/6/2020).Ambos os atores, contudo, ignoraram as contribuições da sociedade civil no processo.

\subsection{Participação e o auxílio emergencial}

A narrativa da articulação das organizações foi feita com riqueza por uma de suas personagens principais, Alessandra Orofino, diretora-executiva da Nossas, no artigo "O Levante" para a Revista Piauí. Nele, Orofino destaca a liderança de ativistas jovens como Douglas Belchior, Pedro Telles e Ricardo Martins, além da

2 https://economia.uol.com.br/noticias/redacao/2020/06/12/deputado-rebate-bolsonaro-sobre-auxilio-nao-admitiam-mais-que-r-200.htm 
própria autora, os quais já possuíam contato e cujas organizações já eram parceiras em diferentes iniciativas.

Este grupo inicial coordenou-se a partir de São Paulo e Rio de Janeiro, característica que também seria traduzida para os interlocutores prioritários do grupo durante a tramitação das propostas sobre o Auxílio Emergencial no parlamento.

Conforme relato de um desses ativistas, Pedro Telles, para a elaboração do presente capítulo, o objetivo dos ativistas era compor o grupo inicial com organizações de diferentes perfis e capacidades de atuação, agrupando atores com experiência em campanha, presença e experiência com atuação em Brasília/DF, familiaridade técnica com o tema, relacionamento com o setor privado e representação dos grupos sociais potencialmente beneficiários.

$\mathrm{O}$ autor do presente capítulo teve a oportunidade única de testemunhar, como convidado, uma dessas reuniões de coordenação, em que se discutiram quais os melhores interlocutores, estratégias e alternativas técnicas para a proposta.

A composição da coalizão também buscou dar respostas a uma potencial vulnerabilidade, apontada pela literatura para as estratégias de advocacy - o questionamento da legitimidade das organizações, versus a representação política eleita (Gozetto, 2018), um problema constante para atores e arranjos que buscam promover ou defender causas, colocando-se de alguma forma na posição de representantes de direitos difusos ou sub-representados na política institucional.

Assim, formou-se um núcleo de organizações constituído por: Nossas, Coalizão Negra por Direitos, INESC (Instituto de Estudos Socioeconômicos), Instituto Ethos e a Rede Brasileira de Renda Básica.

O diagnóstico das organizações era que o rápido lançamento da campanha seria fundamental, pois dificilmente haveria janela de oportunidade melhor para avançar com esta política pública e, ao mesmo tempo, a proposta do Ministério da Economia já ganhava a mídia tradicional, sob a alcunha de "Coronavoucher". 
Com a campanha pronta, o grupo recebeu a adesão das mais de setenta organizações do Pacto pela Democracia, coalizão de organizações fundada em 2018 com perfis e foco de atuação muito distintos, mas que se articulam para monitorar e propor ações coordenadas para manutenção e fortalecimento do espaço democrático no Brasil.

As estratégias simples e efetivas de campanha consistiram na consolidação da proposta do auxílio de R \$ 500,00 mensais, aproveitando o cadastro único já existente para chegar rapidamente aos beneficiários. Todas essas informações foram disponibilizadas em uma página da internet com informações sobre a proposta, compartilhável facilmente em redes sociais para manifestação de apoio.

O senso de oportunidade e agilidade das organizações fez a diferença, ganhando espaço na mídia e apoio de mais de mil influenciadores digitais, que compartilharam a proposta de forma coordenada e impulsionaram sua popularização, chegando à marca de 500 mil assinaturas em apenas cinco dias de campanha. Em pouco tempo, economistas de diferentes correntes teóricas e ideológicas, como Laura Carvalho, Armínio Fraga e Mônica de Bolle, somaram seu apoio à campanha.

Paralelamente, a coalizão formada pelas organizações buscou acessar os canais já consolidados e relacionamentos que mantinham com parlamentares que possuíam alinhamento com a agenda, mas também proximidade com lideranças e especialmente com as presidências da Câmara dos Deputados e do Senado Federal.

De acordo com os membros da coalizão, foram fundamentais as articulações com os deputados Orlando Silva (PCdoB/SP), Tabata Amaral (PDT/SP), Randolfe Rodrigues (Rede/AP), todas já previamente estabelecidas a partir de relacionamentos prévios das organizações que integravam o núcleo das articulações.

Foi oportuno, também, que os parlamentares acima mencionados gozassem de proximidade relativa à cúpula das duas casas legislativas, em especial de Rodrigo Maia (DEM/RJ), presidente da 
Câmara dos Deputados, cujo elevado poder de agenda é consensual na literatura sobre o sistema político brasileiro.

No caso de Orlando Silva, contou a proximidade pessoal e política a Rodrigo Maia, cultivada desde sua primeira eleição para comandar a Mesa Diretora, em 2015. Por outro lado, Tabata Amaral já fora destacada pelo presidente da Câmara e líderes partidários como uma espécie de relatora informal de um conjunto de proposições que visavam ampliar o Bolsa Família, bem como outros programas de proteção social ainda em 2018.

Orlando tornou-se o principal porta-voz da proposta, que ganhou o apoio de líderes da oposição. Não obstante, ganhava corpo nos bastidores a articulação em torno do PL 9.236/2017, mas sem ainda definições quanto a valores e critérios para distribuição.

Contando com o apoio dos parlamentares já mencionados, as organizações passaram a realizar reuniões com diversos deputados, visando dar parâmetros técnicos e políticos para a negociação de texto, com o tensionamento em pontos apontados como fundamentais pela Rede Brasileira de Renda Básica.

Nestas conversas, aponta Pedro Telles, "conseguir dar as respostas técnicas fez toda a diferença. Bolsonaro viu que iria perder e jogou o valor para $\mathrm{R} \$ 600,00$ ”.

Com a consolidação do conteúdo da proposta no processo legislativo, o foco das organizações passou a ser garantir sua efetividade nos passos seguintes do ciclo de políticas públicas, a Regulamentação e a Execução.

Assim, duas propostas das organizações foram encampadas pelos porta-vozes e passaram a constar no texto: que o direito ao cadastramento fosse o mesmo durante os três meses pensados para o auxílio, para que houvesse tempo de que se chegasse a todos os potenciais beneficiários, além do conceito de que, em famílias monoparentais, mulheres recebessem em dobro.

Por fim, no Senado, o porta-voz das organizações - senador Randolfe Rodrigues (Rede/AP) - apresentou o PL 873/2020, que 
expandia os beneficiários e trazia algo fundamental para a coalizão: impedia a apropriação do benefício para cobrança de dívidas. Essa proposição também foi aprovada com rapidez pelo Senado, em 1/4/2020, sendo sancionada em 14/5/2020.

\section{Avaliando a influência das ações de advocacy}

Conforme aponta Mahoney (2007), a mensuração dos resultados de ações de lobby ou advocacy deve levar em consideração que tais interações não se constituem, necessariamente, como jogos de soma zero. Dessa forma, é possível que diversos atores obtenham ganhos simultaneamente, sem que necessariamente para isto seja preciso que outros percam.

"When assessing interest group lobbying success we must consider what they sought and what they got, allowing room for degrees of success", 3 aponta Mahoney (2007), que propõe ao menos três variáveis categóricas distintas para mensuração de sucesso da atuação dos grupos de advocacy: 1) não atingimento de nenhum dos objetivos declarados; 2) atingimento de alguns dos objetivos; e 3) atingimento pleno dos objetivos.

Outro aspecto fundamental para avaliação das estratégias de lobbying diz respeito ao espaço para atuação. Não parece ser um pressuposto forte assumir que regimes políticos menos democráticos serão menos permeáveis aos interesses da sociedade civil e vice-versa. No mesmo sentido, Mahoney (2007) sugere que atores institucionais não sujeitos a accountability eleitoral, mesmo em regimes democráticos, também seriam menos sujeitos a estratégias de advocacy.

Nesse sentido, parece impossível avaliar a atuação das organizações da sociedade civil durante a pandemia de Covid-19 sem ressaltar a relevância de que o Parlamento tenha permanecido aberto

3 Tradução livre: "Ao avaliarmos o sucesso do lobbying de grupos de interesse, devemos considerar o que buscavam e o que conseguiram, deixando margem para gradações do sucesso". 
neste período, em que pese todas as suas limitações extensamente apontadas nesta publicação.

O caso do auxílio emergencial nos parece mais relevante, por ilustrar como uma burocracia insulada no Poder Executivo, no caso o Ministério da Economia, é forçada a mudar sua posição original (voucher de R \$ 200,00) para outra largamente distinta ( $\$$ \$ 600,00 mensais em espécie), em função do processo legislativo e das expectativas eleitorais da Presidência da República, estas sim sujeitas à influência da sociedade civil e da pressão cidadã.

Em seus estudos empíricos sobre o sucesso de estratégias de lobby nos Estados Unidos e na União Europeia, Mahoney (2007) destaca uma série de fatores que podem favorecer seu sucesso, dos quais se destacam o escopo da agenda, o nível de conflito que acarreta, a ocorrência de um evento focal e a saliência do tema para o público em geral. Sumarizamos no quadro 6, a avaliação feita sobre os dois casos destacados anteriormente, com base nos critérios apontados pela autora:

Quadro 6. Avaliação das estratégias de advocacy

\begin{tabular}{lllllll}
\hline Agenda & Objetivo & Sucesso & Escopo & $\begin{array}{l}\text { Confli- } \\
\text { to }\end{array}$ & Evento & $\begin{array}{l}\text { Saliên- } \\
\text { cia }\end{array}$ \\
\hline $\begin{array}{l}\text { MPV } \\
910\end{array}$ & $\begin{array}{l}\text { Evitar a regu- } \\
\text { larização de } \\
\text { terras sujeitas à } \\
\text { grilagem }\end{array}$ & $\begin{array}{l}\text { Atingi- } \\
\text { mento } \\
\text { pleno }\end{array}$ & Limitado & Alto & Não & Não \\
\hline $\begin{array}{l}\text { Auxílio } \\
\text { Emer- } \\
\text { gencial }\end{array}$ & $\begin{array}{l}\text { Renda mensal } \\
\text { de R } 500,00 \\
\text { para pessoas no } \\
\text { cadastro único }\end{array}$ & $\begin{array}{l}\text { Atingi- } \\
\text { mento } \\
\text { pleno }\end{array}$ & Limitado & Baixo & Sim & Sim \\
\hline
\end{tabular}

Fonte: Elaboração própria.

No caso da MP 910, ficou evidenciado pelo depoimento de Rodrigo Maia, presidente da Câmara, o peso das organizações da sociedade civil no processo legislativo, evitando que a matéria fosse 
transformada em lei. Dessa forma, mesmo em uma questão com alto grau de conflito - vide o embate com a Frente Parlamentar Agropecuária e o Planalto -, não prosperou.

Por sua vez, a coalizão sobre a Renda Básica Emergencial teve grande sucesso e contribuição técnica no processo legislativo, ainda que em um ambiente menos conflitivo, visto que o principal adversário era a posição draconiana do Poder Executivo. A estratégia, contudo, favoreceu a criação de um ambiente de consenso em torno da proposta original, que por fim acabou sendo ampliada em um esforço final do Governo para modificar a narrativa política associada à medida.

\section{Conclusão}

A avaliação feita no presente capítulo é sabidamente limitada tanto em escopo (apenas dois casos), quanto em profundidade. No entanto, parece ser suficiente para afirmar que a participação da sociedade civil foi relevante, sem a qual possivelmente os processos teriam tomado rumos distintos.

Algumas características comuns aos casos analisados também chamam a atenção. Em primeiro lugar, as organizações não se furtaram à tentativa de incidir no processo legislativo por meio de estratégias de lobby, a despeito de terem negado o acesso ao espaço físico do Congresso. Todavia, fiaram-se em relacionamentos já previamente estabelecidos para acessar o debate e os bastidores das negociações dos projetos, o que reforça a importância do trabalho perene das organizações para momentos de estresse e afunilamento dos canais de incidência política.

Outro ponto relevante foi o uso combinado de estratégias de comunicação e mobilização em redes sociais, em detrimento de estratégias que privilegiam mídias tradicionais, com uso intensivo de influenciadores digitais como forma de ampliação do público atingido. 
Por fim, a coordenação de diferentes organizações por meio de coalizões mostra-se fundamental, trazendo ganhos de escala para as ações de advocacy, além de suprir parcialmente a escassez de informações políticas, técnicas e de espaços presenciais para articulação durante a pandemia.

\section{Referências}

Gozetto, Andréa. "Relações governamentais como fator de competitividade". Cadernos Adenauer, ano XIX, n. 2, p. 35-50, 2018.

Mahoney, Christine. "Lobbying Success in the United States and the European Union”. Journal of Public Policy, v. 27, n. 1, p. 35-56, 2007.

Mancuso, Wagner e Gozetto, Andréa. "Lobby e políticas públicas no Brasil”. In Lukic, Melina e Tomazini, Carla (org.). As ideias também importam: abordagem cognitiva e politicas públicas no Brasil. Rio de Janeiro: Editora Juruá e FGV - Direito RJ, 2013.

Olson, Mancur. A Lógica da Ação Coletiva. São Paulo: Edusp, 2011.

Orofino, Alessandra. “O levante”. Revista Piauí, n. 164, 2020. Disponível em: https://piaui.folha.uol.com.br/materia/o-levante/ 